\title{
Governança e Inovação em Políticas Públicas: intersecções de uma fértil AGENDA DE PESQUISA ${ }^{1,2}$
}

Pedro Cavalcante ${ }^{3}$

\section{INTRODUÇÃO}

O objetivo deste artigo é discutir os avanços e possíveis caminhos nos estudos sobre duas temáticas essenciais na compreensão do funcionamento da administração pública brasileira e que atualmente estão em destaque no campo das políticas públicas: governança pública e inovação. Essas agendas de pesquisa, nos últimos anos, estruturaram-se na Diretora de Estudos e Políticas do Estado, das Instituições e da Democracia (Diest) do Ipea em um espaço de debate e produção de conhecimento sobre políticas públicas. Elas ganham ainda mais relevância em função da necessária adequação e aplicação dos seus conceitos e teorias ao particular arcabouço político e institucional brasileiro, marcado pela singularidade na combinação de fatores como multipartidarismo, federalismo, participação social, fortalecimento das agências reguladoras, dos sistemas de justiça e de controle, entre outros. Logo, este artigo se justifica como um esforço de reflexão sobre o que já aprendemos, bem como de prospecção sobre temáticas que ainda carecem de pesquisas científicas aplicadas.

A ênfase na intersecção e possível sinergia entre essas duas temáticas se torna central na medida em que a promoção e difusão da inovação no setor público, compreendida como novos produtos, processos, estratégia de comunicação e, sobretudo, serviços que geram valor à população, raramente se efetivam a partir da exclusiva ação estatal. A construção de capacidade inovadora na administração pública é considerada fundamental para enfrentar os problemas públicos, cada vez mais complexos, incertos e transversais, e/ou aprimorar continuamente as ferramentas de gestáo (OCDE, 2015). Nesse sentido, o campo de estudo demonstra que a grande maioria das inovaçóes ocorrem em arranjos de governança pública, ou seja, em um conjunto de dinâmicas relacionais envolvendo múltiplos atores interconectados (governamentais e não governamentais) por instituições formais e informais (Capano, Howlett, Ramesh, 2015; Banco Mundial, 2018; Cavalcante, 2018; 2019b). Portanto, a expansão das pesquisas sobre o funcionamento de diferentes arranjos de governança, bem como sobre parcerias e práticas colaborativas nas políticas públicas, se apresenta como uma estratégia crucial para gerar conhecimento direcionada à construção de capacidades e cultura de inovação no setor público.

Além desta introdução, o trabalho possui mais três seçōes. Na seção 2, desenvolve-se uma síntese dos principais achados das linhas de pesquisas de governança e inovaçáo, desenvolvidas pela Diest nos últimos anos. Na seção 3, temas de interesse para agenda futura são abordados na perspectiva de continuidade e aprofundamento de do campo de estudo nacional. Por fim, na seção 4, são tecidas algumas considerações sobre a contribuição do artigo.

1. DOI: http://dx.doi.org/10.38116/bapi29art6

2. 0 autor agradece os comentários e sugestões de Roberto Rocha C. Pires, Luseni Aquino e Alexandre Gomide.

3. Especialista em políticas públicas e gestão governamental (EPPGG) do Ministério da Economia (ME), atualmente lotado na Diretoria de Estudos e Políticas de Estado, das Instituições e da Democracia (Diest) do Ipea. 


\section{QUE APRENDEMOS}

As investigaçóes sobre o funcionamento do setor público, especialmente o brasileiro, embora não sejam tarefas triviais, são desafiadoras e demandam diferentes frentes de pesquisas, a exemplo das análises sobre capacidades estatais, burocracia e participação social, focos de outros capítulos deste Boletim. Assim como algumas dessas temáticas, governança e inovação também sofrem com o rótulo de "conceito mágico” da administração, isto é, possuem interpretaçôes vagas e imprecisas, com alta carga de juízo de valor e suposta positividade em perspectivas ingênuas (naive) e até irrealistas (Hupe e Pollitt, 2010).

Portanto, diante das dinâmicas transformações de Estado, economia e sociedade, bem como dos avanços teóricos e metodológicos do campo de estudo, as pesquisas desenvolvidas pela Diest sobre governança e inovação em políticas públicas apresentam alguns aprendizados e progressos que merecem destaque.

O primeiro deles envolve o reconhecimento da interface entre governança e inovação no debate contemporâneo de gestão pública. Nas últimas duas décadas, as grandes reformas administrativas foram substituídas por esforços de melhorias constantes e graduais, micro-improvements ou inovaçóes na era do pós-New Public Management (NPM) tanto em nível global (Cavalcante, 2017) quanto doméstico (Cavalcante, 2018; 2019b). Nesse contexto, as inovações ganharam dimensão estratégica e se materializam no setor público a partir da combinação de diferentes tendências nos processos de formulação e implementação, tais como colaboração; redes; accountability e transparência; visão holística e integrada; engajamento social; coordenação; entre outras (Cavalcante, 2018; 2019b).

Nessa direção, recentemente, a Diest também se preocupou em abordar as diversas transformações no papel do Estado, na sua morfologia e nas formas de atuação da administração pública brasileira nos últimos vinte e cinco anos. Os resultados dos estudos de importantes dimensóes da máquina estatal, tais como burocracia, estrutura organizacional, participação social, regulação, concessões etc. demonstram que os caminhos foram variados, pautados por avanços e inovaçóes, mas também por paralisia e inflexão que repercutem em dilemas e desafios persistentes no setor público brasileiro. Como síntese desse processo, pode-se inferir que a grande maioria das mudanças ocorreram de forma incremental e sobrepostas, ou seja, introdução de novas instituiçóes (regras, procedimentos, organizaçóes etc.) em coexistência com as anteriores. As trajetórias e inovações da administração pública federal no Brasil também convergiram com as tendências do modelo ou paradigma da governança ou pós-NPM (Cavalcante e Silva, 2020).

As variedades do conceito de governança, seja para fins de aplicação de arranjos no policy making quanto para fins de análise, também foram objeto de estudo da Diest. Nesse sentido, a coletânea de artigos sobre governança pública (Ipea, 2018) procurou demonstrar, sob diferentes abordagens e enfoques, a multidimensionalidade do conceito e a importância de romper com visáo hegemônica e simplista de que a governança é uma panaceia aos problemas da administração pública e que pode ser resultante de um pacote de reformas predefinido e imposto de forma exógena. O estudo reforça o caráter dinâmico dos arranjos de governança, que são influenciados por diferentes estratégias nem sempre consensuais entre os atores envolvidos e pelas inerentes capacidades das organizaçóes públicas (Ipea, 2018). Assim, almejou-se qualificar a compreensão sobre esse conceito e, sobretudo, alertar para os problemas e riscos da prevalência da visão normativa-prescritiva de governança, acarretando em confusôes e recomendaçóes de práticas que não consideram diferentes realidades complexas, gargalos estruturais e desigualdades existentes dentro do setor público. 
Um quarto aprendizado sobre inovação e governança envolve a importância do papel do Estado. No primeiro caso, prevalece a superação do debate superficial e da falsa dicotomia entre setor público e privado, na medida em que, em um ecossistema de inovação, eles são não apenas fundamentais, mas, sobretudo, complementares. Os papéis do Estado são variados e transitam entre: i) restrição (exemplo dos códigos de ética de pesquisa); ii) condição, como as leis de inovação; iii) catalisador (programas de fomento a empresas nascentes ou start-ups); e iv) agente de iniciativas inovadoras em seus processos e na prestação de serviços públicos (Cunha, 2017). No caso da governança, os arranjos de coordenação e implementação das açóes governamentais náo são mais predominantemente baseados em mecanismos de hierarquia (autoridade, unilateralidade e coerção), uma vez que os mecanismos de redes (confiança e cooperação) e mercado (incentivos e trocas) também coexistem na maioria dos desenhos de políticas públicas. Esse caráter híbrido de mecanismos empregados no policy making pode ser observado, por exemplo, nos estudos sobre a governança da política de infraestrutura (Gomide e Pereira, 2018) e do núcleo de governo na coordenação dos programas prioritários da Presidência da República (Cavalcante et al., 2019).

Outro elo nos estudos de governança e inovação é a presença dos princípios de colaboração, parcerias ou coprodução na implementação das políticas públicas. O componente colaborativo é recorrente, embora longe de ser uniforme, pois varia em termos de atores/organizaçóes e formas de interação entre eles, como também nos instrumentos de gestão e/ou coordenação adotados. Boa parte das iniciativas inovadoras e arranjos de governança em redes ou híbridos se materializam em parcerias a partir de processos dinâmicos, com constantes esforços pautados em tentativa e erro e, principalmente, aprendizagem, como ficam evidentes nas reflexóes sobre governança pública em diferentes perspectivas - regulatória, multinível, corporativa, entre outras (Ipea, 2018), bem como nos casos de inovação em distintos níveis de governo e áreas de políticas e gestão (Cavalcante, 2019a).

A inovação nos últimos anos vem se transformando em um "novo normal” no campo da administração pública, isto é, objetivos, rotinas e discursos em prol da inovação nas organizaçóes públicas vêm cada vez mais se tornando o padrão de normalidade e, logo, parte da agenda estratégica dos governos. Não obstante, essa realidade não é homogênea em todo o setor público, na medida em que as assimetrias de desempenho e de capacidades inovadoras ainda são a regra e não a exceção no país. Os graus de amadurecimento, sofisticação e disseminação de boas práticas variam significativamente entre as áreas de políticas públicas, Poderes da República e esferas de governo (Cavalcante et al., 2017; Cavalcante, 2019a).

Ademais, uma proposição teórica confirmada também nos campos analíticos e aplicados de políticas públicas brasileiros é que inovação consiste em um processo normalmente gradual, complexo e multicausal. Suas implementaçóes e resultados dependem de diferentes indutores, incluindo fatores de natureza ambiental, organizacional, individual e das próprias características da inovação (Cavalcante e Camóes, 2017). Do mesmo modo, a construção de capacidades e cultura de inovação requer componentes combinados em configuraçóes distintas de acordo o tipo de inovação e as características da organização pública, incluindo experimentalismo, coprodução, equipes interdisciplinares, liderança, engajamento do empreendedor público, entre outros (Cavalcante, 2019a).

Por fim, a heterogeneidade também é evidente no âmbito dos arranjos de governança do Poder Executivo, tanto entre os subsistemas de políticas públicas quanto entre o Núcleo de Governo (NdG) e o restante dos ministérios. No caso específico do $\mathrm{NdG}$ brasileiro, os estudos demonstraram que 
não se trata de uma panaceia, ou seja, uma solução para todos os problemas de gestão do governo federal, mas sim de um arranjo de governança diferenciado que demanda esforços contínuos de inovação na complexa coordenação da agenda prioritária do presidente da República. As configuraçóes e padrôes de funcionamento do $\mathrm{NdG}$ são plásticos e dinâmicos, variando de acordo com os estilos presidenciais, a dinâmica democrática, as características do setor da política pública, bem como as conjunturas social e econômica (Cavalcante e Gomide, 2019).

\section{O QUE AINDA É DESCONHECIDO OU INEXPLORADO}

Ao avançarmos nos estudos de inovação e governança pública nos últimos anos, a consequência natural e positiva desse processo é o reconhecimento de que essas são agendas de pesquisa bem férteis nas quais predominam mais questóes a serem exploradas que respostas. Em um esforço propositivo e não exaustivo, esta seção se dedica a apresentar frentes e temas de investigação científica que podem ser focos de aprofundamento.

A primeira dimensão analítica nesse campo remete à estratégia comparativa entre arranjos de governança e práticas inovadoras. Uma linha de pesquisa envolve a abordagem de distintos setores de políticas e organizaçôes públicas na medida em que podem ser úteis para identificar e explicar as diferenças e semelhanças entre elas. Partindo da premissa de que não existe receita pronta (one size fits all) para o sucesso das políticas públicas, análises comparativas auxiliam o mapeamento das características, barreiras e indutores de padróes distintos de desempenho e inovaçóes no setor público, sobretudo, nos processos de implementação das políticas. Em macroáreas governamentais, como a social por exemplo, os elementos que compóem os arranjos de governança (atores, regras, recursos, arenas etc.) da saúde são distintos da educação e assistência social. Assim, compreender quais configuraçóes e estratégias são adequadas e bem-sucedidas em cada ambiente institucional favorece esforços de melhoria de desempenho e a proliferação de práticas inovadoras. $\mathrm{O}$ mesmo se aplica para comparaçóes entre setores, como infraestrutura, meio ambiente, justiça, entre outros.

Estudos comparados também são bem-vindos no âmbito das esferas subnacionais, haja vista que o Brasil notoriamente possui um pacto federativo único no mundo, no qual todos os três entes de governo são autônomos e possuem uma ampla gama de competências. O nosso arcabouço federativo é repleto de variedades, em termos de desafios ao setor público, capacidades, e sobretudo, desempenho, o que propicia, tanto ao campo de estudo quanto à gestão, potencialidade de aprendizado, seja para prevenção de erros de gestão ou proliferação de boas práticas. A comparação entre prefeituras e governos estaduais possui vantagens porque possibilita abordagens qualitativas e quantitativas, dado o grande número de observaçóes no caso nacional. Outro enfoque promissor é de investigar diferentes padróes de governança multinível, entre as esferas de governo, no âmbito do federalismo cooperativo brasileiro.

Além disso, a despeito da validade das recomendações oriundas de experiências de naçóes desenvolvidas, muito presente especialmente nas publicaçôes de organismos multilaterais, é essencial também conhecermos com mais profundidade processos inovadores em países emergentes que compartilham demandas e restriçóes estruturais similares. Assim, elevam-se as chances de gerar subsídios ao debate e à prática inovadora mais apropriados a nossa realidade. Para tanto, um caminho possível são as comparaçóes entre os países em desenvolvimento e/ou suas regióes, como a América Latina, bem como entre governos subnacionais de diferentes naçôes. 
Uma segunda dimensão interessante envolve a temporalidade das políticas públicas. A origem dos estudos de inovação governamental nasce das análises de difusão de Rogers (2003), ainda na década de 1960, e que, no Brasil, avançou bastante nas últimas décadas (Faria, Coêlho e Silva, 2016). Essa linha de pesquisa visa, principalmente, explicar as causas de determinadas açóes governamentais serem proliferadas entre diferentes governos, bem como os processos de adaptaçóes das mesmas às realidades políticas e administrativas. Contudo, outros problemas de pesquisa ainda não receberam a mesma atenção.

Um deles envolve a sustentabilidade tanto das práticas inovaçôes quanto dos arranjos de governança, considerando suas naturezas notoriamente dinâmicas (Rogers, 2003; Capano, Howlett e Ramesh, 2015). Em outras palavras, como e que fatores interferem na manutençáo deles no tempo e nas organizaçôes ou subsistemas de políticas públicas? Como a inovação e a construção de modelos de governança eficazes, em especial de caráter híbrido, consistem em processos perenes e de longo prazo, identificar esses fatores facilitadores tende a contribuir para a continuidade dessas práticas.

As questôes sobre a volatilidade e, principalmente, o desmonte das políticas públicas (policy dismantling) também constituem um caminho promissor de investigação em um país de democracia recente, com sistema político instável, partidos pouco programáticos e heterogeneidade nas capacidades burocráticas entre setores governamentais, Poderes e esferas de governo. No caso do policy dismantling, ou seja, uma forma distinta de mudança da política pública que envolve corte, redução, diminuição ou remoção completa das ações existentes (Bauer et al., 2012), abordar esse fenômeno se tornou ainda mais relevante, devido a sua recorrência no país após a crise política e econômica iniciada em 2015. Esse processo ocorreu em paralelo à alternância do Executivo federal para coalizóes de cunho mais liberal que, entre outras reformas, aprovaram a Emenda Constitucional no 95/2016, conhecido como “Teto dos Gastos”. Como consequência, desde entáo, os orçamentos das áreas sociais vêm sendo reduzido (Cavalcante e Nogueira, 2020) com efeitos sobre a redução e até extinção de programas governamentais.

Outra dimensão de análise central na administração pública é a avaliação, que continua sendo um desafio no campo de estudo, sobretudo, em contexto de crescimento do debate sobre políticas públicas baseadas em evidências (evidence-based policy). Sem dúvida, avançamos muito na inclusão de práticas avaliativas na rotina governamental durante as últimas décadas, contudo, mensurar efetivamente resultados (outputs) e impactos (outcomes) das políticas consiste em um esforço contínuo e permanente do policy making.

No caso específico da inovação, avaliar e mostrar resultados são premissas necessárias para o próprio reconhecimento das melhorias de serviços públicos em processos de mudança. Logo, surgem questóes relevantes de pesquisa: que arranjos de governança são mais efetivos para solucionar determinados problemas públicos? Como mensurar o grau de inovação de uma iniciativa ou organização? Que impactos as inovaçóes em processos e serviços públicos podem ser comprovados e propagados? Essas perguntas afloram diante das dificuldades de avaliar contextos complexos e medir precisamente outputs e outcomes, que muitas vezes, carecem de informaçóes e dados criveis e sistematizados.

Por fim, o foco na coordenação entre atores e organizaçóes, públicos e não governamentais, apresenta-se como outro fator essencial de conexão entre as agendas de governança e inovação. Essa perspectiva converge com o argumento principal deste artigo de que as inovaçóes dificilmente são 
desenvolvidas de maneira unilateral pelo Estado, ou seja, tendem a ser majoritariamente sustentadas em arranjos de governança compostos de uma variedade de atores de dentro e fora do setor público.

Nessa direção, em publicaçóes recentes, o Banco Mundial $(2017 ; 2018)$ vem reforçando o protagonismo de estratégias que fomentem comprometimento, cooperação e coordenação como tripé para arranjos de governança propensos a gerar melhor desempenho na gestão e políticas públicas efetivas e inovadoras. Portanto, as atençōes se voltam às análises acerca dos desenhos dos instrumentos e mecanismos de governança, bem como das subjacentes instituições, isto é, regras do jogo que estruturam as responsabilidades e interaçôes entre setor público, privado e sociedade civil, dentro da perspectiva de colaboração e coprodução, para alcançar esses fins.

\section{CONSIDERAÇÕES FINAIS}

O artigo procurou apresentar um panorama da produção de conhecimento da Diest acerca de questóes essenciais ao funcionamento do Estado brasileiro, com foco nas intersecções entre governança e inovação de políticas públicas. Além disso, em um esforço propositivo e não exaustivo, o trabalho introduziu alternativas de agendas de pesquisa ainda inexploradas com potenciais para aprofundarmos o conhecimento e aprimorar as condiçôes de análise de temas complexos e dinâmicos, tanto para a Academia quanto para os governos.

Cabe salientar, ainda, que, embora não tenha sido foco deste artigo, novas teorias e ferramentas analíticas, ainda embrionárias no campo de estudo no Brasil, possuem potencial para serem aprofundadas empiricamente no caso nacional: abordagens de instrumentos (instrument-based approach) e combinação de políticas públicas (policy mix); competências, habilidades e capacidades em contexto de governança (policy capacity); e abordagem mecanicista para o desenho de políticas (mechanistic framework for policy design).

Nesse sentido, o aprofundamento e a diversificação dos esforços de pesquisa para explicar os processos de políticas públicas se tornam cada vez mais necessários diante dos crescentes, incertos e ambíguos desafios impostos ao setor público em contexto democrático. Do mesmo modo, a variedade de soluçôes para os problemas públicos também vem se modificando, sobretudo, com o compartilhamento de responsabilidades entre governo, sociedade civil e iniciativa privada náo apenas na formação da agenda, mas também na formulação, implementação, avaliação, difusão e aprendizado das políticas públicas. É justamente nesse contexto de parcerias e colaboraçáo entre esses atores que as intersecções entre inovaçóes e governança pública ocorrem, conforme discutido no decorrer deste artigo.

Portanto, uma preocupação central no campo de estudo se direciona à necessidade da contínua qualificação dos debates acadêmico e governamental com subsídios teóricos e empiricamente válidos que ajudem a superar a superficialidade das visôes restritamente normativas e prescritivas, como também os diagnósticos simplórios e estigmatizados da gestáo pública, rotineiramente propagados pela opinião pública. 


\section{REFERÊNCIAS}

BANCO MUNDIAL. Relatório de Desenvolvimento Mundial 2017: governança e a Lei. Washington: Banco Mundial, 2017.

. improving public sector performance: through innovation and inter-agency coordination. Summary of the Global Report, 2018.

BAUER, M. et al. (Eds.) Dismantling public policy: preferences, strategies, and effects. Oxford: Oxford University Press, 2012.

CAPANO, G. et al. (Eds.). Making policies work: first and second order mechanisms in policy design. Cheltehan: Edward Elgar, 2019.

CAPANO, G.; HOWLETT, M. The knowns and unknowns of policy instrument analysis: policy tools and the current research agenda on policy mixes. SAGE Open, 2020.

CAPANO, G.; HOWLETT, M.; RAMESH, M. (Eds.). Varieties of governance: dynamics, strategies, capacities. London: Palgrave, 2015.

CAVALCANTE, P. Gestáo pública contemporânea: do movimento gerencialista ao pós-NPM. Brasília: Ipea, 2017. (Texto para Discussão, n. 2319).

. Innovations in the federal government during the post-New Public Management Era. RAC.

Revista De Administraçáo Contemporânea, v. 22, p. 885-902, 2018.

. (Org.) Inovação e políticas públicas: superando o mito da ideia. Brasília: Ipea, 2019a.

. Tendências inovadoras de gestão nos governos subnacionais brasileiros. Cadernos Gestáo Pública e Cidadania, 2019b.

CAVALCANTE, P.; CAMÕES, M. Inovação pública no brasil: uma visão geral de seus tipos, resultados e indutores. In: CAVALCANTE, P. et al. (Orgs.). Inovaçáo no setor público: teoria, tendências e casos no Brasil. Brasília: Ipea, 2017.

CAVALCANTE, P. et al. Coordenação de programas prioritários sob a perspectiva do núcleo do governo federal (2007-2014). Brasília: Ipea, 2019. (Texto de Discussão, n. 2440).

CAVALCANTE, P; GOMIDE, A. A. O Presidente e seu núcleo de governo: a coordenação do Poder Executivo. Brasília: Ipea, 2019.

CAVALCANTE, P.; NOGUEIRA, R. Crise fiscal e reforma do Estado: uma análise longitudinal das contas públicas federais. In: CAVALCANTE, P.; SILVA, M. Reformas do Estado no Brasil (1995-2020): trajetórias, inovaçóes e desafios. Brasília: Ipea, 2020.

CAVALCANTE, P.; PIRES, R. Governança pública: das prescrições formais à construção de uma perspectiva estratégica para a ação governamental. Boletim de Análise Político-Institucional, n. 19, 2018.

CAVALCANTE, P.; SILVA, M. Reformas do Estado no Brasil (1995-2020): trajetórias, inovaçôes e desafios. Brasília: Ipea, 2020. 
CUNHA, B. Uma análise da construção da agenda de inovação no setor público a partir de experiências internacionais precursoras. In: CAVALCANTE, P. et al. Inovaçáo no setor público: teoria, tendências e casos no Brasil. Brasília: Ipea, 2017.

FARIA, C.A.; COÊLHO, D.; SILVA, S. (Eds.). Difusão de políticas públicas. Santo André: Editora da UFABC, 2016.

FLANAGAN, K., UYARRA, E., LARANJA, M. Reconceptualising the "policy mix" for innovation. Res. Policy, n. 40, v. 5, p. 702-713, 2011.

GOMIDE, A. A.; PEREIRA, A. K. (Eds.). Governança da política de infraestrutura: condicionantes institucionais ao investimento. Rio de Janeiro: Ipea, 2018.

GOMIDE, A. A.; PIRES, R. R. C. (Eds.). Capacidades estatais e democracia: arranjos institucionais de políticas públicas. Brasília: Ipea, 2014.

HUPE, P.; POLLITT, C. The magic of good governance. Policy and Society, v. 13, n. 5, p. 641-658, 2010. IPEA - INSTITUTO DE PESQUISA ECONÔMICA APLICADA. Boletim de Análise Político-Institucional, n. 19, 2018.

OCDE - ORGANIZAÇÃO PARA A COOPERAÇÃO E DESENVOLVIMENTO ECONÔMICO. The innovation imperative in the public sector: setting an agenda for action. Paris: OECD Publishing, 2015.

ROGERS, E. Diffusion of innovations. Nova York: Free Press, 2003.

WU, X.; HOWLETT, M.; RAMESH, M. (Eds.) Policy capacity and governance: assessing governmental competences and capabilities in theory and practice. London: Palgrave Macmillan, 2018. (Studies in the Political Economy of Public Policy). 